\title{
Fourth-Generation ELISA Screening of Blood Donors: A Reliable Alternative to Nucleic Acid Testing
}

\author{
Ayuba $Z,^{I^{*}}$ Damulak OD, ${ }^{1}$ Salawu L, ${ }^{2}$ Jatau ED, ${ }^{1}$ Jasini J, Pam GJ, Egesie OJ. ${ }^{1}$ \\ ${ }^{I}$ Department of Haematology and Blood Transfusion, University of Jos, Jos - Nigeria \\ ${ }^{2}$ Department of Haematology and Immunology, Obafemi Awolowo University, Ile-Ife, Nigeria \\ ${ }^{3}$ Federal Medical Centre Yola, Yola-Nigeria. \\ ${ }^{4}$ Department of Haematology and Blood Transfusion, Jos University Teaching Hospital, Jos-Nigeria
}

*Correspondence: Dr. Ayuba Zakari

Email: ayubanet@yahoo.com $\begin{array}{ll}\text { Article information } & \\ \text { Date Submitted: } & 3 / / 3 / 2021 \\ \text { Date Accepted: } & 13 / 4 / 2021 \\ \text { Date Published: } & 19 / 4 / 2021\end{array}$

\begin{abstract}
The gold standard for HIV screening of blood donors is individual nucleic acid amplification testing (NAT). However, individual NAT testing is cost-prohibitive, especially in a resource-limited setting. The fourth-generation ELISA that detects both p24 antigen and antibody to HIV-1 and 2 has been recommended as the minimum test for HIV to enhance blood transfusion safety and can be an alternative to NAT testing in resource-limited settings. The aim was to assess the performance of a fourth-generation ELISA in use at a regional blood transfusion service using nucleic acid amplification testing on units of screened blood negative to HIV. The study was a cross-sectional study conducted at the National Blood Transfusion Service center and the Plateau State Virology Research Centre, both in Jos, Nigeria. Between August and October 2016, one thousand and eighteen voluntary blood donors were recruited consecutively and had their samples tested using fourth-generation ELISA. One thousand p24 antigen-negative samples were pooled for NAT in an aliquot of 50 samples. All the pools of fifty samples of 1,000 HIV p24 antigen-antibody negative donor blood screened by the fourth-generation ELISA tested negative for HIV RNA on nucleic acid amplification. The yield of pooled NAT for HIV after a fourth-generation ELISA screening of blood donors was found to be zero in this study, thus establishing the fourth-generation ELISA's reliability. Therefore, we recommend adopting the fourth-generation ELISA test as a minimum requirement for blood donor screening.
\end{abstract}

Keywords: HIV, p24 antigen, Fourth-generation ELISA, Pooled NAT.

\section{INTRODUCTION}

$\mathrm{B}$ lood transfusion was a significant route of transmission of HIV in the past. 'As a result of the inoculums' size, transfusion of infected blood is associated with an almost $100 \%$ chance of successfully

\section{How to cite this article}

Ayuba Z, Damulak OD, Salawu L, Jatau ED, Jasini J, Pam GJ, et al. Fourth-Generation ELISA Screening of Blood Donors: A Reliable Alternative to Nucleic Acid Testing. J Biomed Res Clin Pract. 2021;4(1):97-104. doi.org/10.46912/jbrcp.214 transmitting the virus. ${ }^{1}$ However, the introduction of mandatory pre-transfusion screening for Transfusion Transmissible Infections (TTIs) led to a decline in the transmission of HIV through this highly efficient route. ${ }^{2,3}$

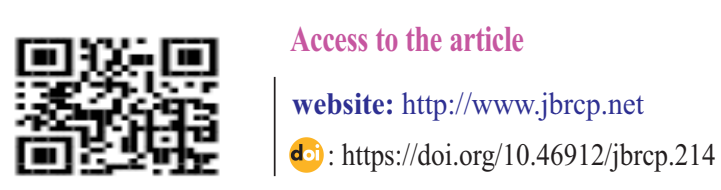


The development of sensitive assays against the HIV p24 antigen and nucleic acids significantly reduces the diagnostic window, permitting earlier detection of the virus $^{4,5}$ The tests based on the detection of viral nucleic acid have been used to identify HIV in pools of blood samples. ${ }^{6}$ With meticulous donor selection, nucleic acidbased testing can further significantly reduce the chances of window period donations and recipients' inoculation. ${ }^{4,5}$ However, running NAT on individual donor samples is expensive, hence not done in most developing nations' blood banks. ${ }^{7}$ Although fourth-generation ELISA is not a substitute for individual NAT, it can be an alternative, cost-effective method for improving blood safety in developing countries. ${ }^{8}$ This study, therefore, seeks to establish the reliability of the fourth-generation ELISA in use at the North-Central regional National Blood Transfusion Service (NBTS).

\section{MATERIALS AND METHODS}

\section{Background of the study area}

The work was carried out at the National Blood Transfusion Service (NBTS) and the Plateau State Human Virology Research Centre (PLASVIREC), Robert Gallo House, Jos, Nigeria. The PLASVIREC is a research Center with active collaborations with the USA Centers for Disease Control and Prevention and the Institute of Human Virology of Nigeria. The Center conducts molecular testing of viruses, among which are the HIV and hepatitis viruses.

\section{Study design}

The study was cross-sectional. Study subjects were blood donors aged 18-65 years recruited during routine donor drives organized by the NBTS. Relevant data were obtained from the subjects with the aid of a selfadministered and researcher-administered questionnaire for literate and uneducated subjects, respectively. The questionnaire addressed the socio-demography of the participants and risk factors for TTIs. Prospective blood donors who consented and passed the donor selection criteria were recruited consecutively.

\section{Sample collection and analysis}

Three-Stage multi-stage sampling was used: all prospective donors who consented to participate in the study were enrolled. After that, selected participants were weighed, and finger-prick blood samples obtained for haemoglobin estimation using the $\mathrm{HemoCue}^{\circledR}$ haematology point of care device. Those whose weight and haemoglobin concentration were within acceptable limits were selected and given a light refreshment, after which venous blood was collected in adult blood bags. Subsequently, $5 \mathrm{ml}$ of blood was expressed from each blood bag tubing into plain vacutainers. The samples obtained were transported in ice packs to the NBTS blood bank, where they were centrifuged, and the sera tested for HIV using a fourth-generation ELISA (Genscreen $^{\text {TM }}$ ULTRA HIV Ag-Ab. Bio-Rad Laboratories-France).

Donor samples tested negative to fourth-generation ELISA were selected, while all those initially sampled who tested positive were excluded. A total of 1,018 plasma samples were collected. The first one thousand fourth-generation ELISA negative samples were selected and pooled for NAT by Real-time Polymerase Chain Reaction, using the COBAS ${ }^{\circledR}$ AmpliPrep/ COBAS ${ }^{\circledR}$ Taqman ${ }^{\circledR}$ HIV-1, v 2.0 (Roche - Germany). The pooling algorithm used was the three-stage hierarchical (D3) pooling, ${ }^{9}$ comprising of a master pool of 50 specimens, an intermediate pool of 25 specimens, and a sub-pool of 5 specimens as follows (Fig. 1):

- Sub-pools of 5 samples (1 through 100) were first created by combining aliquots $(400 \mu \mathrm{L})$ from 5 consecutive individual specimens;

- Intermediate pools of 25 samples (1 through 40) were created by combining aliquots $(400 \mu \mathrm{L})$ from 5 of the sub-pools of 5 ;

- Master pools of $50\left(\mathrm{~A}_{50}\right.$ through $\left.\mathrm{T}_{50}\right)$ were created by combining aliquots $(650 \mu \mathrm{L})$ from 2 intermediate pools of 25 .

All specimens were pooled in duplicate. Only master pools of 50 samples were tested. There was no need to test the intermediate pools further as none of the master pools showed amplification on NAT. 


\section{Quality control}

One COBAS $₫$ TaqMan ${ }^{\circledR}$ Negative Control, one HIV-1 Low Positive Control, and one HIV-1 High Positive Control were included in each test batch.

The assigned titer range for the HIV-1 Low Positive Control and HIV-1 High Positive Control is specific for each lot of reagent and is provided on the COBAS ${ }^{\circledR}$ AmpliPrep/ COBAS $®$ Taqman ${ }$ HIV-1, v 2.0 reagent cassette barcodes. The HIV-1 RNA copies/ml for the positive controls should fall within their assigned titer ranges. If one or both of the positive controls are flagged as invalid, then the entire batch is invalid (COBAS $\mathbb{}$ AmpliPrep/ COBAS ${ }^{\circledR}$ Taqman ${ }^{\circledR}$ HIV-1, v 2.0 User's Manual, Roche-Germany).

The batch was valid when no flag appears for any of the controls. We adhered strictly to the manufacturer's protocol.

\section{Data Analysis}

The data obtained were analyzed using SPSS Statistics for windows version 16.0 2007: Chicago, IL: SPSS Inc. Mean, and Standard deviation (SD) were used to summarize normally distributed continuous variables.

\section{Master pool \\ (50 specimens in each)}

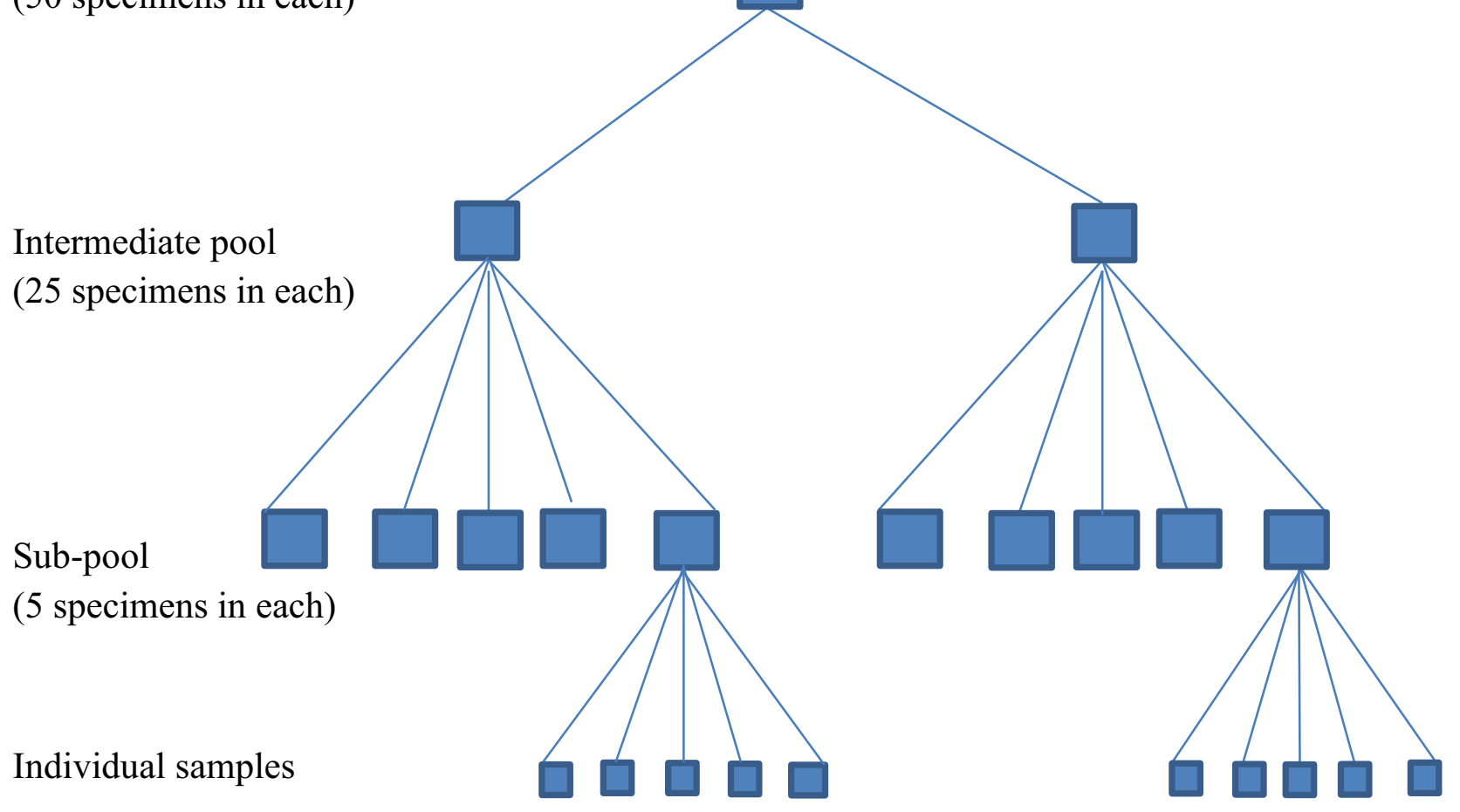

Fig. 1: A schematic diagram of the D3 hierarchical pooling algorithm used in this study. A sub-pool of 5 specimens each was first created from individual samples followed by the combination of 5 sub-pool to create an intermediate pool of 25 specimens. Lastly, two intermediate pools were combined in a single cry-vial to create a Master pool 
Table 1: Interpretation of Result

For a valid batch, the result is interpreted as follows:*

Titer Result

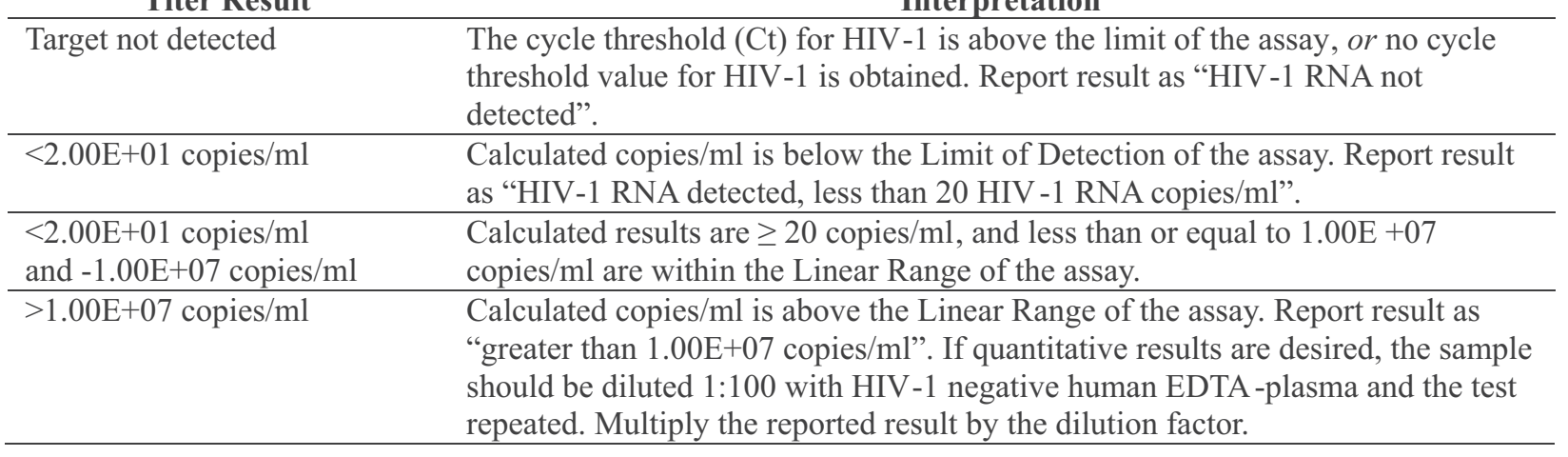

*The table was adapted from COBAS ${ }^{\circledR}$ AmpliPrep/ COBAS ${ }^{\circledR}$ Taqman ${ }^{\circledR} H I V-1, v 2.0$ User's Manual, Roche - Germany.
Chi-Square with Fisher's exact test were used to determine associations between categorical variables. A $\mathrm{p}$-value of $<0.05$ was considered statistically significant. The results obtained were presented in tables.

\section{Ethical consideration}

The study was a part of a larger study titled "The Outcome of Nucleic Acid Amplification Test in HIV p24 AntigenNegative Blood Donors in Jos, Nigeria." The study was undertaken after due approval from the NBTS' Ethical Committee (REF. No: NBTS/EC/EA/44).

\section{RESULTS}

The mean $( \pm \mathrm{SD})$ and participants' median age were $29.7 \pm$ 10.4 and 26 years, respectively. The youngest donor was 18 years, while the oldest was 65 years. There were more males $(69.5 \%)$ than females $(30.5 \%)$ with a male: female of 2.3:1 (Table 4). All the participants (100\%) were voluntary non-remunerated blood donors. First-time and Repeat donors were 703(70.3\%) and 297 (29.7\%), respectively. The frequency of donation among repeat donors ranged from 2 to 17 times.

Of the 703 first-time donors, $3(0.6 \%)$ had a blood transfusion, $8(1.1 \%)$ reported the use of intravenous drugs, $183(26.0 \%)$ engaged in unprotected intercourse, with 24 (3.4\%) having multiple sexual partners. Only $2.9 \%$ and $0.8 \%$ of donors had scarification and tattoo, respectively (Table 4). Among the 297 repeat donors, 1 $(0.3 \%)$ had a blood transfusion, $1(0.3 \%)$ reported the use of intravenous drugs, 97 (32.7\%) engaged in unprotected intercourse, with $13(4.4 \%)$ having multiple sexual partners. Only $2.0 \%$ and $0.7 \%$ of repeat donors had scarification and tattoo, respectively (Table 4). Of the $1000 \mathrm{p} 24$ antigen negative - samples pooled for nucleic acid amplification (20 pools of 50 samples each), none $(0.00 \%)$ showed amplification of the HIV RNA on Real-time Reverse Transcriptase Polymerase Chain Reaction (Table 4). All the pooled samples reported a viral load of $<20$ copies $/ \mathrm{ml}$, which is the lower limit of detection of the COBAS ${ }^{\circledR}$ AmpliPrep/COBAS ${ }^{\circledR}$ TaqMan ${ }^{\circledR}$ HIV-1 Test version 2.0. 
Table 2. Age and Sex distribution of Blood Donors in Jos between August and October 2016.

\begin{tabular}{lccc}
\hline Age group & Male & Female & Total \\
\hline $18-27$ & $367(52.8)$ & $203(66.6)$ & $570(57.0)$ \\
$28-37$ & $165(23.7)$ & $41(13.4)$ & $206(20.6)$ \\
$38-47$ & $105(15.1)$ & $35(11.5)$ & $140(14.0)$ \\
$48-57$ & $45(6.5)$ & $19(6.2)$ & $64(6.4)$ \\
$58-67$ & $13(1.9)$ & $7(2.3)$ & $20(2.0)$ \\
\hline Total & $695(69.5)$ & $305(30.5)$ & $1000(100.0)$ \\
\hline
\end{tabular}

Table 3. Risk factors for HIV infection among Blood donors in Jos between August and October 2016

\begin{tabular}{|c|c|c|c|c|c|}
\hline \multirow[t]{2}{*}{ Risk factor } & \multicolumn{3}{|c|}{ Donor Type } & \multirow[t]{2}{*}{$\mathbf{X 2}$} & \multirow[t]{2}{*}{ p-value } \\
\hline & First $n=703(\%)$ & Repeat $n=297(\%)$ & $\begin{array}{l}\text { Total } \\
n=1000(\%)\end{array}$ & & \\
\hline \multicolumn{6}{|c|}{ Blood transfusion } \\
\hline Yes & $3(0.6)$ & $1(0.3)$ & $4(0.6)$ & & \\
\hline No & $700(99.4)$ & $297(99.7)$ & $996(99.4)$ & & 0.837 \\
\hline \multicolumn{6}{|l|}{ IV drugs } \\
\hline Yes & $8(1.1)$ & $1(0.3)$ & $9(0.9)$ & & \\
\hline No & $697(98.9)$ & $296(99.7)$ & $991(99.1)$ & & 0.294 \\
\hline \multicolumn{6}{|c|}{ Unprotected sexual intercourse } \\
\hline Yes & $183(26.0)$ & $97(32.7)$ & $280(28.0)$ & & \\
\hline No & $520(74.0)$ & $200(67.3)$ & $720(72.0)$ & 4.551 & 0.033 \\
\hline \multicolumn{6}{|c|}{ Scarification } \\
\hline Yes & $23(3.3)$ & $6(2.0)$ & $29(2.9)$ & & \\
\hline No & $680(96.7)$ & $291(98.0)$ & $971(97.1)$ & 1.145 & 0.285 \\
\hline \multicolumn{6}{|l|}{ Tattoo } \\
\hline Yes & $6(0.9)$ & $2(0.7)$ & $8(0.8)$ & & \\
\hline No & $697(99.1)$ & $295(99.3)$ & $992(99.2)$ & & $>0.999$ \\
\hline \multicolumn{6}{|c|}{ Multiple sexual partners } \\
\hline Yes & $24(3.4)$ & $13(4.4)$ & $37(3.7)$ & & \\
\hline No & $679(96.6)$ & $284(95.6)$ & $963(96.3)$ & 0.543 & 0.461 \\
\hline
\end{tabular}

*fishers exact derived p-value

Table 4. Outcomes of NAT on HIV-p24 antigen and antibody - Negative donor blood samples in Jos between August and October 2016

\begin{tabular}{lll}
\hline Sample Pool $\quad \boldsymbol{N}=\mathbf{2 0}$ & Viral Load (Copies/ml) & Interpretation \\
\hline Master Pools (A50-T50) & $<20$ (No amplification) & Target not detected \\
\hline None of the 20 master pools showed amplification on Real -time Reverse \\
Transcriptase Polymerase Chain Reaction.
\end{tabular}




\section{DISCUSSION}

This study assessed the performance of a fourthgeneration (Bio-Rad Genscreen ${ }^{\mathrm{TM}}$ ) assay in use at a regional NBTS by subjecting ELISA-negative samples to nucleic acid amplification testing.

Of the one thousand fourth-generation ELISA-negative p24 samples, none was reactive when subjected to Realtime PCR. This finding is similar to that reported by Chigurupati et al. ${ }^{10}$ and Chaurasia et al. ${ }^{11}$ in 2015 and 2016, respectively. Other studies, however, reported a positive yield after ELISA-negative samples were subjected to nucleic acid amplification. Kumar et al. ${ }^{12}$ in 2015 reported that 1 out of 32,978 samples was positive for HIV on NAT but seronegative with a fourthgeneration ELISA. Selim et al. ${ }^{13}$ reported that mini-pool NAT interdicted 2 HIV samples out of 12,032 seronegative donations in Saudi Arabia, giving a NAT yield of 1 in 6,016 donations. In contrast to that used in this study, the larger sample size used in the above studies might have contributed to NAT's positive findings on fourth-generation ELISA-negative samples.

Based on the outcome of pooled NAT in this study, none of the blood donors was found to have a second diagnostic window- a period that coincides with the absence of specific antibodies and a decline of p24 antigen below the detection limit of the fourth-generation ELISA. Our finding is at variance with reports by others who found a second diagnostic window with the fourth-generation ELISA. ${ }^{14,15}$

The zero yields of NAT in this study may result from the category of blood donors recruited. All the subjects in this study were voluntary non-remunerated blood donors considered the safest category of blood donors. More often than not, voluntary blood donors seem sure of themselves regarding TTI's, and in particular, HIV. The absence of NAT yield in this study may also be due to the method used: pooled specimen as against individual NAT. This was possible because of the potential for progressive dilution of a positive sample with increasing pool size. Westreich et al. ${ }^{9}$ reported that an increase in pool size from 16 to 100 reduced the likelihood of HIV detection by 15 to $30 \%$. Choosing a NAT with a lower limit of detection of $<20$ viral copies $/ \mathrm{ml}$, such as the one used in carrying out this research, may minimize the effect of increasing pool sizes on the pooling algorithm sensitivity. In one systemic review by Abubakar et al. ${ }^{16}$ in 2015, pooled NAT's clinical sensitivity was put at $100 \%$ for a pool size of 10 to 50 donor plasma. Although pooled NAT has an advantage over individual NAT in terms of cost, its major drawback is the delay in releasing donated units to the recipients. Pooled NAT can serve as an additional safety layer and may be added to the HIV screening protocol, especially among highrisk populations. Additionally, samples from retained donors can be pooled in a batch of 20 or 25 and subjected to NAT.

After running NAT on the pooled samples, all samples were reported to have a viral load of $<20$ copies $/ \mathrm{ml}$; this is the lower limit of detection of the COBAS ${ }^{\circledR}$ AmpliPrep/COBAS ${ }^{\circledR}$ TaqMan ${ }^{\circledR} H I V-1$ Test version 2.0. All specimens that did not show amplification or flags were reported to have a viral load of $<20$ copies $/ \mathrm{ml}$ and target not detected. The implication of this is that a positive sample with a viral load below the instrument's detection limit would be assumed to be negative. Thus, a negative test does not necessarily imply non-infectivity. Negative findings in this study may also be a result of the system's design. The COBAS ${ }^{\circledR}$ AmpliPrep/COBAS ${ }^{\circledR}$ TaqMan ${ }^{\circledR} H I V-1$ Test version 2.0 only detects HIV-1 and not HIV-2. The HIV-2 is present in the West African Subcontinent where this study was done, and co-infection is not uncommon, especially among sex workers. ${ }^{17}$ Although HIV-1 and HIV-2 show similarities in virion structure and overall genome organization, ${ }^{18}$ test systems designed for HIV-1 cannot be relied on to detect HIV-2. Human Immunodeficiency Virus is notorious for its ability to mutate, which may cause the TaqMan ${ }^{\circledR}$ to miss the targeted sequence and, therefore, show no amplification. 
The fourth-generation ELISA's performance in this study shows that it can be relied upon for blood donor screening in our setting, providing a cost-effective alternative to NAT.

\section{CONCLUSION}

Our study found a zero yield of pooled NAT for HIV after fourth-generation ELISA screening of blood donors. This finding was in agreement with other studies, thus confirming the fourth-generation ELISA's reliability for blood donor screening in our environment. We recommend adopting the fourth-generation ELISA as the minimum test for TTIs; however, additional tests for blood safety are advocated.

\section{Limitations}

Due to the high cost of running individual NAT on donated blood units, pooled NAT was used to assess the Fourth-generation ELISA's reliability in this study.

Financial Support and Sponsorship: None.

Conflict of Interest: There is no conflict of interest.

\section{REFERENCES}

1. Baggaley RF, Boily MC, White RG, Alary M. Risk of HIV-1 transmission for parenteral exposure and blood transfusion: a systematic review and metaanalysis. AIDS (London, England). 2006;

20:805-812.

DOI:10.1097/01.aids.0000218543.46963.6d

2. Stanic HS, Babic I, Maslovic M, Dogic V, Bingulac-Popovic J, Miletic M, Jurakovic-Loncar N, Vuk T, Strauss-Patko M, Jukic I. Three-year experience in NAT screening of blood donors for transfusion transmitted viruses in Croatia.

Transfusion medicine and hemotherapy. 2017; 44:415-20. DOI:10.1159/000457965

3. Fiedler SA, Oberle D, Chudy M, Scheiblauer H,
Henseler O, Halbauer J, Heiden M, Funk M. Effectiveness of blood donor screening by HIV, HCV, HBV-NAT assays, as well as HBsAg and anti-HBc immunoassays in Germany (2008-2015). Vox Sanguinis. 2019; 114:443-50. DOI:10.1111/vox. 12770

4. Hans R, Marwaha N. Nucleic acid testing-benefits and constraints. Asian Journal of Transfusion Science. 2014; 8:2-3. DOI:10.4103\%2F09736247.126679

5. Cohen MS, Gay CL, Busch MP, Hecht FM. The detection of acute HIV infection. The Journal of Infectious Diseases. 2010; 202(Supplement_2):S270-7. DOI:10.1086/655651

6. Chandrashekar S. Half a decade of mini-pool nucleic acid testing: Cost-effective way for improving blood safety in India. Asian Journal of Transfusion Science. 2014; 8:35-38. DOI:10.4103\%2F0973-6247.126688

7. Gosh K, Mishra K. Nucleic acid amplification testing in Indian blood banks: A review with perspectives. Indian J Pathol Microbiol. 2017; 60:313-8.

8. Bhattacharya P, Kaur R. Implementing fourth generation human immunodeficiency virus enzyme-linked immunosorbent assay: One step forward in blood safety. Asian Journal of Transfusion Science. 2013; 7:107-8. [Google Scholar]

9. Westreich DJ, Hudgens MG, Fiscus SA, Pilcher CD. Optimizing screening for acute human immunodeficiency virus infection with pooled nucleic acid amplification tests. Journal of Clinical Microbiology. 2008; 46:1785-1792. DOI:10.1128/JCM.00787-07

10. Chigurupati P, Murthy KS. Automated nucleic acid amplification testing in blood banks: An additional layer of blood safety. Asian journal of transfusion science. 2015; 9:9-11. DOI: $\underline{10.4103 / 0973-6247.150938}$ 
11. Chaurasia R, Rout D, Zaman S, Chatterjee K, Pandey HC, Maurya AK. Comparison of Procleix Ultrio Elite and Procleix Ultrio NAT Assays for Screening of Transfusion Transmitted Infections among Blood Donors in India. International Journal of Microbiology. 2016; 16:1-7. DOI:10.1155/2016/2543156

12. Kumar R, Gupta S, Kaur A, Gupta M. Individual donor-nucleic acid testing for human immunodeficiency virus-1, hepatitis $C$ virus and hepatitis B virus and its role in blood safety. Asian journal of transfusion science. 2015; 9:199-202. DOI:10.4103/0973-6247.154250

13. Selim HM, El-Bashaar MA, El-Wakil SG. Donor mini-pool NAT screening for HBV, HCV, and HIV: a 2-year experience in a private hospital in Saudi Arabia. Comparative Clinical Pathology. 2014; 23:1125-1132. DOI:10.1007/s00580-013-1751-3

14. George CR, Robertson PW, Lusk MJ, Whybin R, Rawlinson W. Prolonged second diagnostic window for human immunodeficiency virus type 1 in a fourth-generation immunoassay: are alternative testing strategies required? Journal of clinical microbiology. 2014; 52:4105-8. DOI:10.1128/JCM.01573-14

15. George CR, Robertson PW, Lusk MJ, Whybin R, Rawlinson W. Prolonged second diagnostic window for human immunodeficiency virus type 1 in a fourth-generation immunoassay: Are alternative testing strategies required? Journal of Clinical Microbiology. 2014; 52:4105-4108. DOI:10.1128/JCM.01573-14

16. Abubakar AG, Ozumba PJ, Buttner P, Winter J, Abimiku A. Current Trends in the detection of Acute HIV Infection among Blood Donors: Reliability of Pooled Nucleic Acid Amplification Technology and the Need for Population Specific Algorithms: A Systematic Review. Journal of Antivirals \& Antiretrovirals. 2015; 7:89-103. DOI:10.4172/JAA.1000124

17. Papworth E, Ceesay N, An L, Thiam-Niangoin M,
Ky-Zerbo O, Holland C, Dramé FM, Grosso A, Diouf D, Baral SD. Epidemiology of HIV among female sex workers, their clients, men who have sex with men and people who inject drugs in West and Central Africa. Journal of the International AIDS Society. 2013; 16:18751. DOI:10.7448/IAS.16.4.18751

18. Pachulska-Wieczorek K, Stefaniak AK, Purzycka KJ. Similarities and differences in the nucleic acid chaperone activity of HIV-2 and HIV-1 nucleocapsid proteins in vitro. Retrovirology. 2014; 11:1-3. DOI:10.1186/1742-4690-11-54 